\title{
PARAFAC2 and MCR-ALS quantification of Diltiazem antihypertensor based on a kinetic spectrophotometric methodology
}

\author{
João M.M. Leitão ${ }^{\text {, }}$, Joaquim C.G. Esteves da Silva ${ }^{\text {b,* }}$ \\ ${ }^{a}$ Laboratório de Métodos Instrumentais de Análise, Faculdade de Farmácia da Universidade de Coimbra, \\ Centro de Estudos Farmacêuticos, 3000-432 Coimbra, Portugal \\ ${ }^{\mathrm{b}}$ Centro de Investigação em Química, Departamento de Química, Faculdade de Ciências da Universidade do Porto, \\ R. Campo Alegre 687, 4169-007 Porto, Portugal
}

Received 2 January 2007; received in revised form 11 June 2007; accepted 11 June 2007

Available online 16 June 2007

\begin{abstract}
A Diltiazem kinetic spectrophotometric UV-Vis method, based on a reaction of the Diltiazem with hidroxylamine and a ferric salt, was used for the quantification of Diltiazem in different pharmaceutical formulations. This method is based on the acquisition of three-way data structures [wavelength $(\mathrm{nm}) \times$ time $(\mathrm{s}) \times$ concentration $(\mathrm{mg} / \mathrm{L})$ ] followed by chemometric analysis by an appropriate PARAFAC 2 or MCR-ALS second-order calibration model. The results obtained are compared with those obtained by direct determination, at maximum wavelength, and by the United States Pharmacopeia (USP) standard chromatographic method. For all the pharmaceutical formulations analysed good quantification results were found with PARAFAC2 and MCR-ALS second-order calibration models. For bulk drug analysis, detection limits of 6 and $2 \mathrm{mg} / \mathrm{L}$, and for pharmaceutical formulations analysis, an average detection limit of 41 and $39 \mathrm{mg} / \mathrm{L}$ were found, respectively with PARAFAC2 and MCR-ALS.
\end{abstract}

(C) 2007 Elsevier B.V. All rights reserved.

Keywords: Diltiazem antihypertensor; Kinetic UV-Vis spectroscopy; Quantification; Bulk drug; Pharmaceutical formulations; PARAFAC2; MCR-ALS

\section{Introduction}

Diltiazem, one of the major cardiovascular drug, is a calcium channel blocker widely use as an anti-anginal and antihypertensive agent $[1,2]$. The analysis of therapeutic compounds in pharmaceutical formulations constitutes a mixture analysis problem because these formulations always contain excepients. In the United States Pharmacopeia (USP) the official method for the determination of Diltiazem in bulk drug, in extended-release capsules and in tablets formulations is a HPLC-UV method [1]. In the European Pharmacopeia the official method for the determination in bulk drug is a potentiometric titration [2].

Several methods were developed for its quantification but most of the methods for the determination of Diltiazem in bulk drug, pharmaceuticals formulations and biological fluids are based in chromatographic separative techniques [3-15]. The spectrophotometric methodologies are a good alternative to the separative techniques due to cheaper and lower time of analysis

\footnotetext{
* Corresponding author. Fax: +351 226082959.

E-mail address: jcsilva@fc.up.pt (J.C.G. Esteves da Silva).
}

and to the generation of few waste products. Some spectrophotometric methods, based on derivatisation reactions, were developed for Diltiazem quantification in bulk drug and pharmaceutical formulations [16-22]. To some of these methods a reaction time of about 40 min was observed $[16,17]$ and with others an extractive step is needed [18-22].

In this paper a new method for the quantification of Diltiazem in pharmaceutical formulations with a lower time of analysis, no extractive step and maximum sensitivity, based on a previously optimized colour development reaction, is presented [23]. The acquisition of a spectrum as function of the reaction time and concentration of Diltiazem (standards and samples) allows the arrangement of the data set to a third order tensor. Besides the chemical selectivity obtained by the colour development reaction a further improvement of selectivity can be obtained with multiway chemometric analysis of the experimental data. With this approach neither the extraction nor the separation of the analyte from the background are needed.

Several second-order models, with different trilinearity assumptions, can be used for multi-way analysis. In this paper two models will be used: parallel factor analysis 2 (PARAFAC2) 
[24]; and, multivariate curve resolution-alternating least squares (MCR-ALS) [25]. Both models, in a different way, allow small deviations to the trilinear model. PARAFAC2 allows deviation of the trilinearity in one dimension and MCR-ALS allows deviation of the trilinearity in all the components or in some of them.

Several methods have been proposed for the analysis of three-dimensional kinetic spectrophotometric data obtained by different experimental procedures [26-32]. Besides models that allow deviations to the trilinearity of three-dimensional data, as PARAFAC2 [26,27], MCR-ALS [28-31] and three-dimensional Tucker (TUCKER3) [32], models that assume rigorous trilinear three-dimensional data, as parallel factor analysis (PARAFAC) [26,28,33-39], trilinear decomposition (TLD) [36] and the n-way partial least squares (NPLS) [28,33,35,38] have been proposed for the analysis of this kind of data.

The objective of this paper is to propose a new method for the analysis of Diltiazem in pharmaceutical formulations based on a three-dimensional kinetic spectrophometric method coupled to chemometric decomposition methods of PARAFAC2 and MCR-ALS. Four pharmaceutical formulations were used to assess the performance of the new methodology and the results were compared with those obtained by a USP standard chromatographic method.

\section{Experimental}

\subsection{Reagents}

Diltiazem reference standard ( $\geq 99 \%$ purity), ammonium ferric sulphate (99\% purity) and hydroxylamine hydrochloride $(98 \%$ purity) were obtained from SIGMA-ALDRICH Química S. A. (Spain). Sodium hydroxide and methanol for liquid chromatography were purchased from Merck, Darmstadt (Germany). Deionised water with resistivity higher than $4 \mathrm{M} \Omega / \mathrm{cm}$ was used.

Pharmaceutical formulations with different dosage, from 60 to $200 \mathrm{mg}$ of Diltiazem, were chosen for this study. The pharmaceutical formulations were Alandiem ${ }^{\circledR}$ tablets $60 \mathrm{mg}$ from Zimaia (Al60ta), Balcor ${ }^{\circledR}$ Retard capsules $90 \mathrm{mg}$ from Baldacci (Ba90re), Herbesser ${ }^{\circledR}$ SR 120 extended release capsules $120 \mathrm{mg}$ from Delta (He120sr) and Diltiem ${ }^{\circledR}$ AP 200 extended release capsules $200 \mathrm{mg}$ from Sanofi (Dtap).

\subsection{Solutions}

Previous to the preparation of the Diltiazem standard stock solutions by rigorous weighting of the solid powder, Diltiazem was dried during two hours in an oven at $105^{\circ} \mathrm{C}$.

For the quantification with a previously optimized kinetic spectrophotometric UV-Vis method [23] a $4000 \mathrm{mg} / \mathrm{L}$ Diltiazem standard stock solution prepared in methanol, was used. Aqueous solutions prepared by rigorous weighting of hydroxylamine hydrochloride $(18.750 \%)$ and sodium hydroxide $(37.500 \%)$ and perchloric acid $7.000 \%(\mathrm{w} / \mathrm{w})$ solutions of ammonium ferric sulphate $(2.000 \%)$ were also used. The hydroxylamine reagent (hydroxilamine $9.375 \%$ / sodium hydroxide $18.750 \%$ ) used for the colour development reaction was obtained by mixing equal volumes of the aqueous hydroxylamine hydrochloride (18.750\%) and sodium hydroxide (37.500\%) solutions. The sample solutions were prepared by rigorous weighting of a mass equivalent to one tablet or capsule from a mixture of 20 tablets or capsules, obtained after grounding and homogenization, in methanol for a final concentration of $4000 \mathrm{mg} / \mathrm{L}$. To separate insoluble excepients present in the pharmaceutical formulations, sample solutions were centrifuged at $13000 \mathrm{rpm}$ during $10 \mathrm{~min}$.

All the dilutions were obtained with methanol for a final volume of $2.5 \mathrm{~mL}$ in the $1 \mathrm{~cm}$ quartz cells used for spectra acquisition. Except for the perchloric acid addition the different dilutions of the reagents in the different concentrations used were obtained by adding a fixed volume of the initial solutions.

For the quantification with the USP chromatographic method the mobile phase, standard stock solutions and sample solutions were prepared according the USP recommendations [1]. The mobile phase is prepared as a mixture of a buffer solution (1.16 $\mathrm{g}$ of d-10-camphorsulonic acid in $1000 \mathrm{~mL}$ of $0.1 \mathrm{M}$ sodium acetate adjusted to $\mathrm{pH} 6.2$ with sodium hydroxide), acetonitrile and methanol (50:25:25). The standard stock and sample solutions were prepared in methanol by rigorous weighting for a final concentration of $2000 \mathrm{mg} / \mathrm{L}$. Diluted standard and sample solutions were obtained by dilution with methanol to the required concentrations.

\subsection{Instrumentation}

Spectral acquisition was made in a Hewlett-Packard HP8452A diode-array spectrophotometer in advanced mode. Spectra were collected with the shutter open, wavelength range from 400 to $800 \mathrm{~nm}$ with a $2 \mathrm{~nm}$ interval, run time $30 \mathrm{~s}$, cycle time $1 \mathrm{~s}$ and an integration time $0.5 \mathrm{~s}$.

HPLC determinations were made with a system constituted by a HP1100 isocratic pump, a manual injection valve Rheodyne model 7752i, a Rheodyne $20 \mu \mathrm{L}$ loop, a pre-column Agilent $(20 \mathrm{~mm} \times 4 \mathrm{~mm})$ coupled to a Supelco column $(100 \mathrm{~mm} \times 4.6 \mathrm{~mm})$ Hypersil $^{\circledR}$ ODS with $3 \mu \mathrm{m}$ particle diameter and a diode array detector (DAD) Ati Unicam Crystal 250 model. The DAD acquired spectra in a wavelength range from 220 to $472 \mathrm{~nm}$ with a resolution of $2 \mathrm{~nm}$.

\subsection{Analytical methodologies}

The quantification of Diltiazem with the kinetic spectrophotometric UV-Vis method was performed in a $1 \mathrm{~cm}$ quartz cells for a total volume of $2.5 \mathrm{~mL}$ with a standard addition method with four experimental data points. For an expected concentration of $150 \mathrm{mg} / \mathrm{L}$ of Diltiazem in bulk drug and in pharmaceutical formulations solutions, and in order to obtain Diltiazem standard concentrations of 50, 150 and $250 \mathrm{mg} / \mathrm{L}$, additions of 30, 90 and $150 \mu \mathrm{L}$ of the $4000 \mathrm{mg} / \mathrm{L}$ Diltiazem standard solution were done.

Within the quartz cell the mixture of the reagents is done by stirring with a micro magnetic bar. The order of reagents addition is: (i) suitable volume of Diltiazem bulk drug or pharmaceutical formulation solution; (ii) suitable volume of methanol to $0.500 \mathrm{~mL}$ (attending to the previous added volume); (iii) $0.300 \mathrm{~mL}$ of hydroxylamine reagent; (iv) suitable volume of methanol to $2.5 \mathrm{~mL}$ (attending to the all the volumes added); (v) minimum volume of perchloric acid $7.000 \%$ to neutralize the sodium 
hydroxide previous added $(0.410$ to $0.430 \mathrm{~mL})$ (vi) $0.100 \mathrm{~mL}$ of ammonium ferric sulphate. The addition of ammonium ferric sulphate is made after the acquisition of the spectra has started.

The chromatographic quantification of Diltiazem with the USP method (flow rate of $1.6 \mathrm{~mL} / \mathrm{min}$ and detection at $240 \mathrm{~nm}$ ), following the USP recommendations, was performed using an external standard method of calibration. The quantification for each of the samples, bulk drug and pharmaceutical formulations, was done with three determinations.

\subsection{Chemometric analysis}

The three-way data structures are obtain by the acquisition of UV-Vis spectra as function of the reaction time following the kinetic reaction and at different concentrations of Diltiazem obtained by a standard addition method [wavelength $\times$ time $\times$ concentration]. For the direct determination of Diltiazem the absorbance intensity values at maximum wavelength are collected from the matrix of experimental data.

The two second-order models used in the analysis of the three-way data structure are the PARAFAC2 and the MCR-ALS models [24,25]. PARAFAC2 model of $K$ matrices arranged as a third order tensor is defined as Eq. (1):

$\mathbf{X}_{k}=\mathbf{A} \mathbf{D}_{k}\left(\mathbf{P}_{k} * \mathbf{H}\right)^{T}+\mathbf{E}_{k}=\mathbf{A} \mathbf{D}_{k} \mathbf{B}_{k}^{T}+\mathbf{E}_{k}, k=1, \ldots K$

$\mathbf{X}_{k}$ is the $k$ matrix of the $K$ matrices $\left(\mathbf{X}_{l}, \ldots, \mathbf{X}_{k}\right), \mathbf{A}$ is the first dimension loadings $(I \times N)$ matrix where $N$ is the number of components, $\mathbf{D}_{k}$ is the diagonal matrix with elements from 1 to $N$ that holds the $k$ th row of the third dimension loadings $\mathbf{C}$ $(K \times N)$ matrix, $\mathbf{H}$ is an $(N \times N)$ scaling matrix, $\mathbf{P}_{k}$ is an orthonormal $(J \times N)$ matrix in which $J$ can vary with $K$ and $\mathbf{E}_{k}$ is the $K$ matrix of the residuals three-way data structure of $K$ matrices. The $\mathbf{B}_{k}$ is the $(J \times N) K$ matrix of the second dimension loadings obtained by of $\mathbf{P}_{k} * \mathbf{H}$.

MCR-ALS model of $K$ matrices $\left(\mathbf{X}_{1}, \ldots, \mathbf{X}_{k}\right)$ arranged as a bidimensional column-wise data matrix is defined as Eq. (2):

$\mathbf{X}_{k}^{\prime}=\mathbf{A}_{k} \mathbf{B}^{T}+\mathbf{E}_{k} \Longleftrightarrow\left[\begin{array}{c}\mathbf{X}_{1} \\ \vdots \\ \mathbf{X}_{k}\end{array}\right]=\left[\begin{array}{c}\mathbf{A}_{1} \\ \vdots \\ \mathbf{A}_{k}\end{array}\right] \mathbf{B}^{T}+\left[\begin{array}{c}\mathbf{E}_{1} \\ \vdots \\ \mathbf{E}_{k}\end{array}\right]$,

$k=1, \ldots K$

$\mathbf{X}_{k}{ }^{\prime}$ is the column-wise bidimensional data matrix of the $K$ matrices of the three-way data structure, $\mathbf{A}_{k}$ is the first and third dimension loadings $(L \times N)$ matrix where $L=I \times K$ and $N$ is the number of components, $\mathbf{B}^{T}$ is the second dimension loadings $(N \times J)$ matrix and $\mathbf{E}_{k}$ is a $L \times N$ matrix of residuals.

The data matrices initially analysed with PARAFAC2 were structured as three-way data structures [wavelength $(\mathrm{nm}) \times$ time $(\mathrm{s}) \times$ concentration $(\mathrm{mg} / \mathrm{L})]$ and with MCR-ALS were structured as column-wise bidimensional data structures [(concentration (mg/ L) $\times$ time $(\mathrm{s})) \times$ wavelength $(\mathrm{nm})]$. For the MCR-ALS model data matrices structured as column-wise bidimensional data [(concentration $(\mathrm{mg} / \mathrm{L}) \times$ wavelength $(\mathrm{nm})) \times$ time(s)] were also analysed.

The estimations in the two models were obtained using an iterative alternating least squares regression with the two models using the adequate constraints. The initial estimates used for the two models were estimates of a model without constraints. In order to obtain the initial estimates of the models without constraints an initial analysis with the PARAFAC2 model was performed with initial estimates of SVD and with the MCR-ALS model with initial estimates of pure variables obtained by SIMPLISMA (SIMPLe-to use Interactive Self-modelling Mixture Analysis). The analysis of the data structures was performed with non-negativity constraints in the first and third dimensions for the PARAFAC2 model and in the two dimensions for the MCR-ALS model. With the MCR-ALS model other natural constraints as the trilinearity constraint were used. As convergence criteria a value of $1 \times 10^{-7}$ and $1 \times 10^{-3}$ and a maximum number of iterations of 2000 and 50 were used respectively with the PARAFAC2 and MCR-ALS.

The model evaluation was done with the model fit, sum squares of residuals (SSQr) and the iterations number. The

Table 1

Quantification of the bulk drug with UV-Vis direct, UV-Vis PARAFAC2, UVVis MCR-ALS and HPLC-UV methodologies*

\begin{tabular}{|c|c|c|c|}
\hline & \multicolumn{3}{|c|}{$\mathrm{UV}-\mathrm{Vis}\left(C_{\text {Expected }}=150.0 \mathrm{mg} / \mathrm{L}\right)$} \\
\hline & Direct & PARAFAC2 & MCR-ALS \\
\hline $\begin{array}{r}C_{\text {Estimated }} \\
(\mathrm{mg} / \mathrm{L})\end{array}$ & $156.7(4.9)$ & $143.7(3.0)$ & $150.5(1.1)$ \\
\hline $\begin{array}{c}\text { Recovery } \\
(\%)\end{array}$ & 104.5 & 95.71 & 100.3 \\
\hline $\operatorname{DL}\left(3 \mathrm{~s}_{\mathrm{y} / \mathrm{x}} / \mathrm{b}\right)$ & 9.943 & 6.318 & 2.271 \\
\hline
\end{tabular}

Model evaluation

$\begin{array}{llll}\text { Fit }(\%) & - & 99.487 & 97.338 \\ \text { SSQr } & - & 0.084 & 2.087 \\ \text { Iterations } & - & 2000 \text { (maximum) } & 28 \\ R_{\text {Spectrum }} & - & +0.711 & +0.842 \\ R_{\text {Reaction time }} & - & +0.592-+0.526 & +0.701-+0.701 \\ & & +0.358-+0.415 & +0.701-+0.701\end{array}$

Calibration $(y=b x+a, m=4)$

$\begin{array}{llll}\text { a } & 0.3156(0.0051) & 0.2625(0.0030) & 0.2205(0.0009)\end{array}$

$\begin{array}{llll}\text { b } & 2.014 \times 10^{-3} & 1.827 \times 10^{-3} & 1.465 \times 10^{-3}\end{array}$

$\left(\begin{array}{lll}\left(3.475 \times 10^{-5}\right) & \left(2.003 \times 10^{-5}\right) & \left(5.772 \times 10^{-6}\right) \\ \left(6.674 \times 10^{-3}\right. & 3.848 \times 10^{-3} & 1.109 \times 10^{-3}\end{array}\right.$

$\begin{array}{llll}\mathrm{s}_{\mathrm{y} / \mathrm{x}} & 6.674 \times 10^{-3} & 3.848 \times 10^{-3} & 1.109 \times 10^{-3}\end{array}$

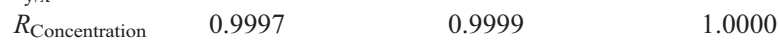

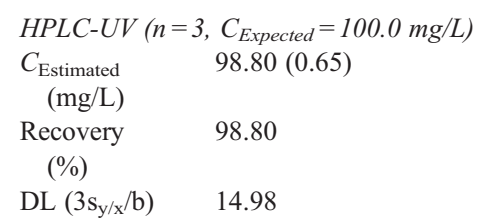

* The values in brackets are the standard deviation of the extrapolated concentration, intercept and slope calculated with two degrees of freedom; $C_{\text {Estimated, }}$, concentration estimated; DL, detection limit; Fit, model fit; SSQr, sum squares of residuals; $R_{\text {Spectrum }}$, calculated correlation coefficient between the estimated and the rough spectrum of the principal coloured product; $R_{\text {Reaction time, }}$ calculated correlation coefficient between the estimated and the rough reaction time profile of the principal coloured product; $m$, number of experimental data points for calibration; $\mathrm{s}_{\mathrm{y} / \mathrm{x}}$, standard deviation of the residuals; $R_{\text {Concentration, }}$ is the calculated correlation coefficient between the estimated and expected concentrations of the principal coloured product; $n$, number of determinations. 
Table 2

Quantification of the pharmaceutical formulations with UV-Vis direct, UV-Vis PARAFAC2, UV-Vis MCR-ALS and HPLC-UV methodologies*

\begin{tabular}{|c|c|c|c|c|}
\hline & \multicolumn{4}{|c|}{ Pharmaceutical formulations } \\
\hline & Al60ta & Ba90re & He120sr & Dtap \\
\hline \multicolumn{5}{|c|}{$U V-$ Vis direct $\left(C_{\text {Expected }}=150.0 \mathrm{mg} / \mathrm{L}\right)$} \\
\hline $\begin{array}{r}C_{\text {Estimated }} \\
(\mathrm{mg} / \mathrm{L})\end{array}$ & $155.2(10.8)$ & $152.5(16.3)$ & $154.9(14.4)$ & $155.5(23.4)$ \\
\hline $\begin{array}{c}\text { Recovery } \\
(\%)\end{array}$ & 103.7 & 101.4 & 103.3 & 103.1 \\
\hline $\mathrm{DL}\left(3 \mathrm{~s}_{\mathrm{y} / \mathrm{x}} / \mathrm{b}\right)$ & 21.90 & 33.32 & 29.06 & 47.45 \\
\hline DOS $_{\text {Estimated }}$ & 62.95 & 91.22 & 123.9 & 206.3 \\
\hline PE $(\%)$ & 15.20 & 12.99 & 12.02 & 4.00 \\
\hline$R_{\text {Concentration }}$ & 0.9986 & 0.9967 & 0.9975 & 0.9933 \\
\hline \multicolumn{5}{|c|}{$U V$-Vis PARAFAC2 $\left(C_{\text {Expected }}=150.0 \mathrm{mg} / \mathrm{L}\right)$} \\
\hline $\begin{array}{r}C_{\text {Estimated }} \\
(\mathrm{mg} / \mathrm{L})\end{array}$ & $138.9(7.4)$ & $132.5(16.7)$ & $137.6(26.7)$ & $147.3(25.1)$ \\
\hline $\begin{array}{c}\text { Recovery } \\
(\%)\end{array}$ & 92.81 & 88.04 & 91.72 & 97.73 \\
\hline $\operatorname{DL}\left(3 \mathrm{~s}_{\mathrm{y} / \mathrm{x}} / \mathrm{b}\right)$ & 15.78 & 36.56 & 57.41 & 52.12 \\
\hline DOS $_{\text {Estimated }}$ & 55.68 & 79.33 & 110.1 & 195.5 \\
\hline $\mathrm{PE}(\%)$ & 1.901 & 2.916 & 0.506 & 1.462 \\
\hline \multicolumn{5}{|c|}{ Model evaluation } \\
\hline Fit $(\%)$ & 99.32 & 99.56 & 99.70 & 99.66 \\
\hline SSQr & 0.129 & 0.038 & 0.026 & 0.020 \\
\hline Iterations & $\begin{array}{l}2000 \\
\text { (maximum) }\end{array}$ & $\begin{array}{l}2000 \\
\text { (maximum) }\end{array}$ & $\begin{array}{l}2000 \\
\text { (maximum) }\end{array}$ & $\begin{array}{l}2000 \\
\text { (maximum) }\end{array}$ \\
\hline$R_{\text {Spectrum }}$ & +0.695 & +0.962 & +0.913 & +0.910 \\
\hline$R_{\text {Reaction time }}$ & $\begin{array}{l}-0.548- \\
-0.038 \\
-0.142- \\
-0.373\end{array}$ & $\begin{array}{l}+0.869- \\
+0.936 \\
+0.924- \\
+0.905\end{array}$ & $\begin{array}{l}+0.294- \\
-0.024 \\
+0.918- \\
+0.909\end{array}$ & $\begin{array}{l}+0.119- \\
+0.181 \\
+0.750- \\
+0.083\end{array}$ \\
\hline$R_{\text {Concentration }}$ & 0.9993 & 0.9960 & 0.9902 & 0.9919 \\
\hline \multicolumn{5}{|c|}{$U V-V i s$ MCR-ALS $\left(C_{\text {Expected }}=150.0 \mathrm{mg} / L\right)$} \\
\hline $\begin{array}{r}\mathrm{C}_{\text {Estimated }} \\
(\mathrm{mg} / \mathrm{L})\end{array}$ & $137.4(3.3)$ & $142.6(12.2)$ & $137.4(15.7)$ & $146.8(42.3)$ \\
\hline $\begin{array}{c}\text { Recovery } \\
(\%)\end{array}$ & 91.83 & 94.77 & 91.58 & 97.16 \\
\hline $\operatorname{DL}\left(3 \mathrm{~s}_{\mathrm{y} / \mathrm{x}} / \mathrm{b}\right)$ & 7.165 & 25.78 & 33.94 & 88.41 \\
\hline DOS $_{\text {Estimated }}$ & 55.10 & 85.29 & 109.9 & 194.7 \\
\hline $\mathrm{PE}(\%)$ & 0.835 & 4.500 & 0.654 & 1.834 \\
\hline \multicolumn{5}{|c|}{ Model evaluation } \\
\hline Fit $(\%)$ & 96.49 & 97.24 & 97.34 & 95.90 \\
\hline SSQr & 3.442 & 1.504 & 1.981 & 2.783 \\
\hline Iterations & 47 & 26 & 14 & 14 \\
\hline$R_{\text {Spectrum }}$ & $\begin{array}{l}+0.840- \\
+0.840 \\
+0.840- \\
+0.840\end{array}$ & +0.972 & +0.860 & +0.982 \\
\hline$R_{\text {Reaction time }}$ & -0.423 & $\begin{array}{l}+0.960- \\
+0.960 \\
+0.960- \\
+0.960\end{array}$ & $\begin{array}{l}+0.924- \\
+0.924 \\
+0.924- \\
+0.924\end{array}$ & $\begin{array}{l}+0.934- \\
+0.934 \\
+0.934- \\
+0.934\end{array}$ \\
\hline$R_{\text {Concentration }}$ & 0.9998 & 0.9980 & 0.9966 & 0.9773 \\
\hline \multicolumn{5}{|c|}{$H P L C-U V\left(n=3, C_{\text {Expected }}=100.0 \mathrm{mg} / L\right)$} \\
\hline $\begin{array}{r}\mathrm{C}_{\text {Estimated }} \\
(\mathrm{mg} / \mathrm{L})\end{array}$ & $91.27(1.03)$ & $90.76(3.88)$ & 92.37 (1.72) & $99.22(3.09)$ \\
\hline $\begin{array}{c}\text { Recovery } \\
(\%)\end{array}$ & 91.08 & 90.69 & 92.18 & 99.18 \\
\hline DOS $_{\text {Estimated }}$ & 54.65 & 81.62 & 110.6 & 198.4 \\
\hline
\end{tabular}

model fit (\%) for the PARAFAC2 model is defined according the Eq. (3) and for the MCR-ALS is defined according the Eq. (4).

$$
\begin{aligned}
& \text { PARAFAC2Fit }(\%)=100 \\
& \times\left(1-\sqrt{\frac{\sum_{i=1}^{I} \sum_{j=1}^{J} \sum_{k=1}^{K}\left(x_{i j k}-\hat{x}_{i j k}\right)^{2}}{\sum_{i=1}^{I} \sum_{j=1}^{J} \sum_{k=1}^{K}\left(x_{i j k}\right)^{2}}}\right) \\
& M C R-A L S F i t(\%)=100 \times\left(1-\sqrt{\frac{\sum_{l=1}^{L} \sum_{j=1}^{J}\left(x_{l j}-\hat{x}_{l j}\right)^{2}}{\sum_{j=1}^{J} \sum_{l=1}^{L}\left(x_{l j}\right)^{2}}}\right)
\end{aligned}
$$

In Eqs. (3) and (4), respectively for the PARAFAC2 and MCR-ALS models, $\hat{x}_{i j k}$ and $\hat{x}_{l j}$ is the $i j k$ and $l j$ element of the estimated data matrix and the $x_{i j k}$ and $x_{l j}$ is the $i j k$ and $l j$ element of the experimental data matrix.

Also, in order to evaluate the estimates obtained in the three dimensions, the correlation coefficient of the estimates of the principal coloured product is calculated for each of the dimensions. The correlation coefficients were calculated between the estimated spectra and the rough experimental spectra, between the estimated reaction time profile and the rough experimental time reaction profile and between the estimated concentrations and the standard addition concentrations.

The evaluation of the quantification obtained by the UV-Vis direct, PARAFAC2 and MCR-ALS methodologies was done by comparison with the quantification obtained by the HPLC-UV analytical methodology through the calculation of the prediction error (PE). PE was calculated according the Eq. (5) attending to the dosage obtained by each of these methodologies and the dosage obtained by the HPLC-UV analytical methodology.

$\operatorname{PE}(\%)=\sqrt{\frac{\left(D_{i}-\hat{D}_{i}\right)^{2}}{\left(D_{i}\right)^{2}}} \times 100$

In Eq. (5) $D_{i}$ is the dosage estimated by the USP HPLC-UV methodology and $\hat{D}_{i}$ is the dosage estimated by the direct, PARAFAC2 or MCR-ALS methodologies. Also, in the pharmaceutical formulations, a comparison of the overall concentrations estimated by the different methodologies was performed by the paired $\mathrm{t}$ and the $\mathrm{F}$ two samples tests at $95 \%$ confidence level $(p=0.05)$.

\section{Notes to Table 2}

* The values in brackets are the standard deviation of the extrapolated concentration calculated with two degrees of freedom; $C_{\text {Estimated, }}$ concentration estimated; DL, detection limit; $D_{\text {Estimated, }}$ Dosage estimated; PE, prediction error; Fit, model fit; SSQr, sum squares of residuals; $R_{\text {Spectrum, calculated correlation coefficient }}$ between the estimated and the rough spectrum of the principal culoured product; $R_{\text {Reaction time }}$, calculated correlation coefficient between the estimated and the rough reaction time profile of the principal coloured product; $R_{\text {Concentration, }}$ is the calculated correlation coefficient between the estimated and expected concentrations of the principal coloured product; $n$, number of determinations. 
Table 3

PARAFAC2 and MCR-ALS model fit conditions used in the analysis of the pharmaceutical formulations

\begin{tabular}{|c|c|c|c|c|}
\hline $\begin{array}{l}\text { Three-way data structure } \\
\text { analysed }\end{array}$ & $\begin{array}{l}\text { Components } \\
\text { number }\end{array}$ & $\begin{array}{l}\text { Restrictions (PARAFAC2 in the } 1 \text { st and } 3 \text { rd and MCR-ALS } \\
\text { in the two dimensions) }\end{array}$ & Initial estimates & $\begin{array}{l}\text { Pharmaceutical } \\
\text { formulations }\end{array}$ \\
\hline \multicolumn{5}{|l|}{ PARAFAC2 model fit conditions } \\
\hline $\begin{array}{l}\text { Wavelength }(\mathrm{nm}) \times \text { time } \\
(\mathrm{s}) \times \text { concentration }(\mathrm{mg} / \mathrm{L})\end{array}$ & $\begin{array}{l}4 \\
5 \\
4\end{array}$ & Non negativity & $\begin{array}{l}\text { PARAFAC2 without } \\
\text { restrictions } \\
\text { SVD }\end{array}$ & $\begin{array}{l}\text { Ba90re } \\
\text { Dtap and He120sr } \\
\text { Al60ta }\end{array}$ \\
\hline \multicolumn{5}{|l|}{ MCR-ALS model fit conditions } \\
\hline $\begin{array}{l}(\text { Concentration }(\mathrm{mg} / \mathrm{L}) \times \text { time } \\
(\mathrm{s})) \times \text { wavelength }(\mathrm{nm})\end{array}$ & $\begin{array}{l}3 \\
3\end{array}$ & $\begin{array}{l}\text { Non negativity and trilinearity in the coloured compound } \\
\text { Non negativity and trilinearity in the coloured } \\
\text { and initial compounds }\end{array}$ & $\begin{array}{l}\text { MCR-ALS without } \\
\text { restrictions }\end{array}$ & $\begin{array}{l}\text { Ba90re and He120sr } \\
\text { Dtap }\end{array}$ \\
\hline $\begin{array}{l}(\text { Concentration }(\mathrm{mg} / \mathrm{L}) \times \\
\quad \text { wavelength }(\mathrm{nm})) \times \text { time }(\mathrm{s})\end{array}$ & 3 & Non negativity and trilinearity in the coloured compound & & Al60ta \\
\hline
\end{tabular}

In order to evaluate the detection capability of each of the methodologies, the corresponding detection limits (DL) were estimated from the residuals standard deviation of the univariate regression line of the absorbance (direct analysis) or the concentrations estimates (PARAFAC2 and MCR-ALS) as function of the Diltiazem concentrations of standards in the calibration by the standard addition method. Similarly, an estimative of the detection limit of the USP methodology was obtained from the standard calibration curve.

PARAFAC2 and MCR-ALS procedures, implemented in MATLAB code, were obtained from http://www.models.kvl.dk/ source/nwaytoolbox/ and http://www.ub.es/gesq/mcr/ndownload. $\mathrm{htm})$, respectively.

\section{Results and discussion}

\subsection{Direct analysis}

Tables 1 and 2, show the results of the direct UV-Vis, multi-way UVVis and USP HPLC-UV analysis of the bulk drug and pharmaceutical formulations, respectively. The comparison of the results obtained by

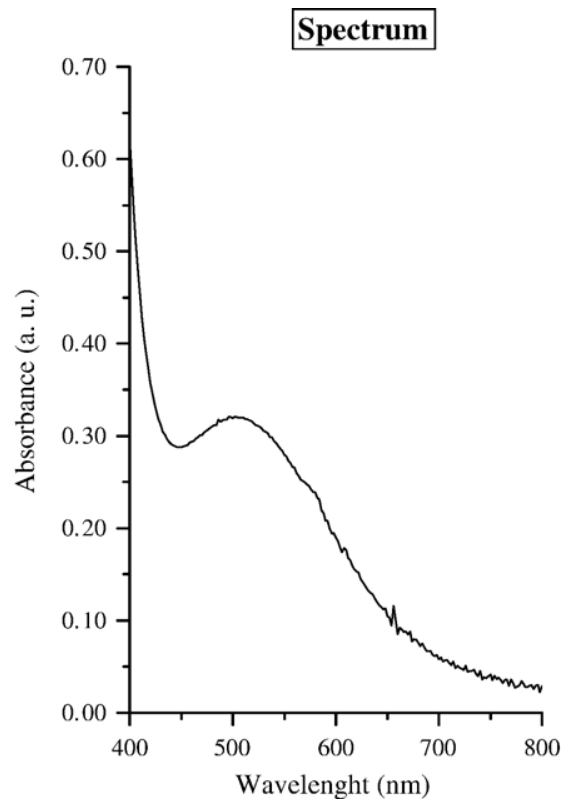

direct UV-Vis and by USP HPLC-UV methods present in these tables shows that the direct analysis gives relatively high estimates for the concentration of Diltiazem. For example, in the case of the bulk drug analysis about $105 \%$ recovery was obtained with direct analysis while with the HPLC method about $99 \%$ recovery was obtained. For the pharmaceutical formulations higher differences are usually observed-the direct analysis allows estimations between 101 to $104 \%$ recovery while the HPLC method gives between 91 to $99 \%$ recovery. Prediction errors higher than $12 \%$ are found by direct analysis for three of the four pharmaceutical formulations evaluated. The high estimations obtained by direct analysis are probably due to background effects, because the chemical background of the samples is more complex, which will be corrected using multi-way analysis. The concentrations estimated by direct and the estimated by PARAFAC2 or MCR-ALS, evaluated by the paired $t$ and the F tests, are significantly different at $95 \%$ confidence level- the $p$ values between the direct and PARAFAC2 were 0.009 and 0.017 , respectively, and between the direct and MCR-ALS were 0.011 and 0.040 , respectively.

\subsection{Multi-way analysis}

For the bulk drug and for some of the pharmaceutical formulations the best estimated concentrations were found with the same model fit

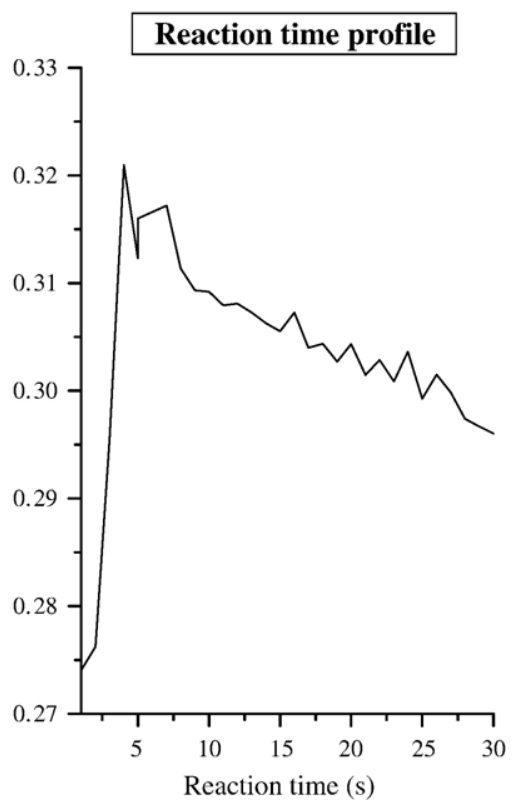

Fig. 1. Rough experimental spectrum and reaction time profile of a Diltiazem standard $150.0 \mathrm{mg} / \mathrm{L}$ at maximum absorbance intensity (reaction time $4 \mathrm{~s}$ and wavelength $502 \mathrm{~nm}$ ). 
conditions. With PARAFAC2 the best estimated concentration was obtained with a model of four components, non negativity and initial estimates by a PARAFAC2 model without constraints in the analysis of a three-way data structure [wavelength $(\mathrm{nm}) \times$ time $(\mathrm{s}) \times$ concentration $(\mathrm{mg} /$ L)]. In the fit by this model the first and third component are the baseline with background absorbance, the second component are the initial compounds and the fourth component is the main coloured compound.

With MCR-ALS the best concentration estimations were obtained with a model of three components, non negativity, trilinearity in the coloured compound and initial estimates by a MCR-ALS model without constraints in the analysis of a bidimensional data structure $[$ concentration $(\mathrm{mg} / \mathrm{L}) \times$ time $(\mathrm{s})) \times$ wavelength $(\mathrm{nm})]$. In the fit by this model the first component are the initial compounds, the second component is the main coloured compound and the third component is the baseline with background absorbance.
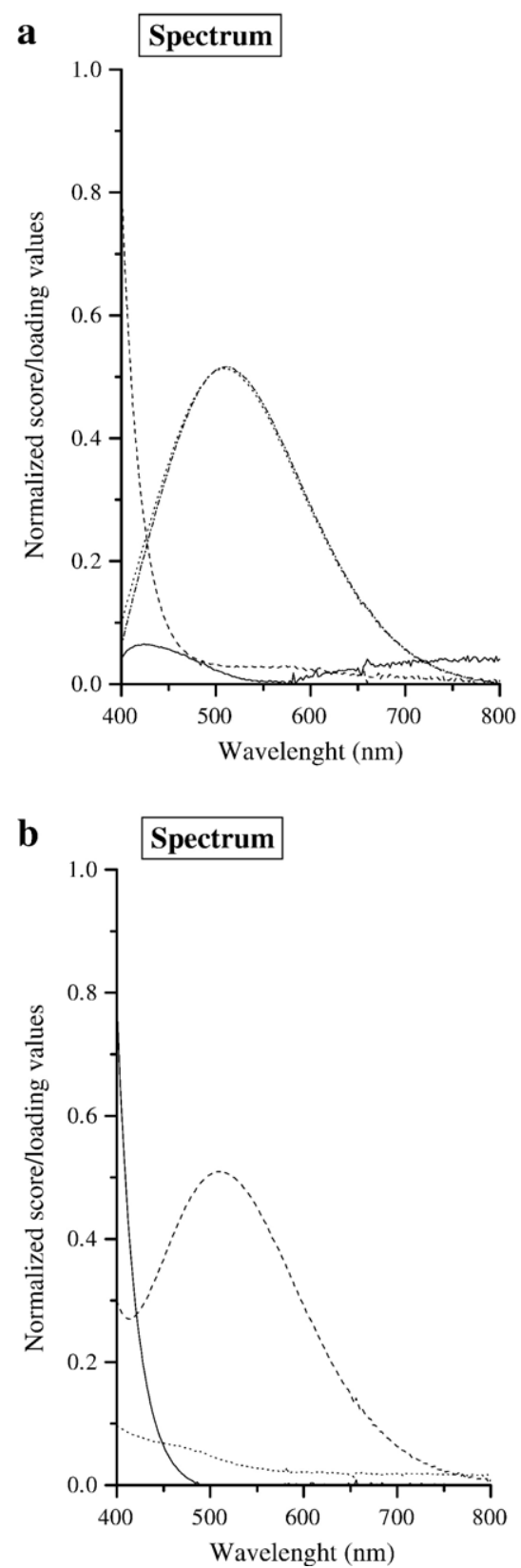

Table 3 resumes the information about the multi-way model characteristics in the analysis of the pharmaceutical formulations. For each of the second-order calibration methods used the best estimated concentration for three, PARAFAC2, and for two, MCRALS, of the pharmaceutical formulations were obtained with different model fit conditions. For better PARAFAC2 model estimation and for the higher dosage pharmaceutical formulations (He120sr and Dtap) a fifth component and for the lower dosage of the pharmaceutical formulations (Al60ta) initial estimations by SVD are needed. For better MCR-ALS model estimation and for the highest dosage pharmaceutical formulation (Dtap) the trilinearity constraint also in the initial compounds and for the lower dosage of the pharmaceutical formulations (A160ta) the analysis of the threeway data structure $[($ concentration $(\mathrm{mg} / \mathrm{L}) \times$ wavelength $(\mathrm{nm})) \times$ time (s)] are needed.
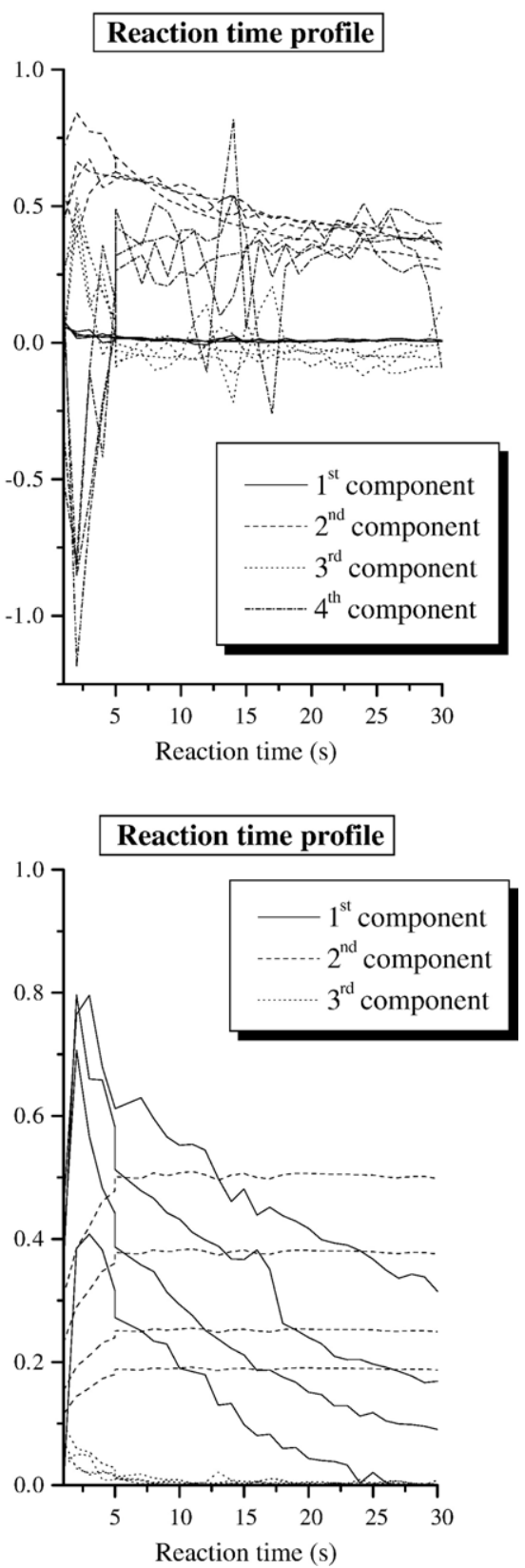

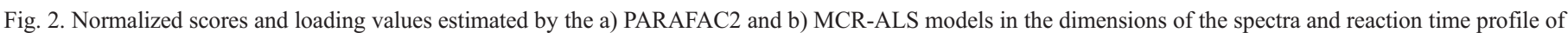
absorbance intensity with the time. 
As shown in Tables 1 and 2 both multi-way analyses give better estimative than those obtained by direct analysis. The prediction errors found by PARAFAC2 and MCR-ALS methodologies are lower than the prediction errors found by direct analysis. This result shows that multi-way analysis compensates for the presence of background signals and allows Diltiazem concentration estimations in pharmaceutical formulations similar to the USP method. Also, PARAFAC2 always gives higher model fits than MCR-ALS- PARAFAC2 originates fits of about $99 \%$ while MCR-ALS originates fits of about $97 \%$.

For the pharmaceutical formulations the concentrations estimated by PARAFAC2 and MCR-ALS are not significantly different as resulted from the analysis by the paired $\mathrm{t}$ and $\mathrm{F}$ test at $95 \%$ confidence level - the $p$ values were 0.519 and 0.313 , respectively. Nevertheless, for three of the four pharmaceutical formulations under analysis, lower prediction errors are obtained with PARAFAC2.

The DL that characterize the four methods for Diltiazem quantification are shown for the bulk drug in Table 1 and for the pharmaceutical formulations in Table 2. For the bulk drug the multi-way methods have the lowest detection limits with 6 and $2 \mathrm{mg} / \mathrm{L}$ for PARAFAC2 and MCRALS, respectively- the USP chromatographic method has a DL of $15 \mathrm{mg} /$ L. For the pharmaceutical formulations an average of the detection limit of 33, 41 and $39 \mathrm{mg} / \mathrm{L}$ were found, respectively with direct, PARAFAC2 and MCR-ALS methodologies. For two of the pharmaceutical formulations (Table 2) the lowest detection limit was found with MCR-ALS and for the other two by direct analysis.

Fig. 1 shows the rough experimental spectrum and reaction time profile and Fig. 2 shows typical results of the PARAFAC2 and MCRALS spectral and reaction profiles components. Indeed, besides the concentration estimations multi-way methods allow the estimation of the spectra and reaction profiles of the components that constitutes the samples under analysis. Attending to the obtained rough experimental spectrum and reaction time profile and to the expected experimental spectrum and reaction time profile a greater correlation coefficient for the spectra and a lowest correlation coefficient for the reaction time profile could be accepted as criteria of better estimates. As shown by the $R_{\text {spectrum }}$ present in Tables 1 and 2, the absorbance spectra of the coloured product of the reaction that constitutes the basis of the kinetic method can be well estimated either by PARAFAC2 or MCR-ALS decomposition methods. Also, the reaction profiles can be well estimated by these two methods. Generally better spectra and reaction time profile estimates are found by the MCR-ALS decomposition method.

\section{Conclusions}

Diltiazem quantification in bulk drug and pharmaceutical formulations by PARAFAC2 and MCR-ALS methodologies gave similar results as those obtained by the USP standard chromatographic method. Similar quantification results were obtained with PARAFAC2 and MCR-ALS methodologies.

For good quantification of Diltiazem different chemometric methods require different number of components and different specific constraints. Also, for analysis of different samples by the same chemometric method different models are usually necessary to achieve better model fit conditions. This result shows that for each sample under analysis the calibration and prediction model always needs optimization.

\section{References}

[1] United States Pharmacopoeia Convention, ed. USP 29, NF 24-The United States Pharmacopoeia, The national Formulary, Rockville, 2006.
[2] European Pharmacopeia, Council of Europe ed. 1st vol. and supplement 4.1, 2001.

[3] M.G. Quaglia, E. Donati, S. Fanali, E. Bossù, A. Montinaro, F. Buiarelli, J. Pharm. Biomed. Anal. 37 (2005) 695-701.

[4] J.L. Buur, R.E. Baynes, J.L. Yeatts, G. Davidson, T.C. DeFrancesco, J. Pharm. Biomed. Anal. 38 (2005) 60-65.

[5] E. Molden, G.H. Bøe, H. Christensen, L. Reubsaet, J. Pharm. Biomed. Anal. 33 (2003) 275-285.

[6] V. Andrisano, P. Hrelia, R. Gotti, A. Leoni, V. Cavrini, J. Pharm. Biomed. Anal. 25 (2001) 589-597.

[7] H. Christensen, E. Carlson, A. Åsberg, L. Schram, K.J. Berg, Clin. Chim. Acta 283 (1999) 63-75.

[8] F. Mangani, G. Luck, C. Fraudeau, E. Vérette, J. Chromatogr., A 762 (1997) 235-241.

[9] G. Carigan, K. Carrier, S. Laganière, M. Lessard, J. Chromatogr., B 672 (1995) 261-269.

[10] M.D. Hussain, Y.K. Tam, B.A. Finegan, R.T. Coutts, J. Chromatogr., B 582 (1992) 203-209.

[11] H.J.C. das Neves, M.D.R.G. da Silva, M.P. Rocha, J. Pharm. Biomed. Anal. 9 (1991) 941-947.

[12] P. Hubert, P. Chiap, J. Crommen, J. Pharm. Biomed. Anal. 9 (1991) 877-882.

[13] P.M. Lacroix, N. Bealieu, T.D. Cyr, E.G. Lovering, J. Pharm. Biomed. Anal. 78 (1989) 243-246.

[14] M.E. Abdel-Hamid, M.S. Suleiman, N.M. Najib, H. Muti, Anal. Lett. 21 (1988) 2263-2275.

[15] J.P. Clozel, G. Gaillé, Y. Taeymans, P. Théroux, P. Biron, F. Trudel, J. Pharm. Sci. 73 (1984) 771-773.

[16] M.M. Ayad, A. Shalaby, H.E. Abdellatef, M.M. Hosny, Anal. Bioanal. Chem. 376 (2003) 710-714.

[17] C.S.P. Sastry, K. Sreedhar, M.N. Reddy, D.G. Sankar, Indian J. Pharm. Sci. 57 (1995) 170-172.

[18] N. Rahman, S.N. Hejaz-Azmi, J. Pharm. Biomed. Anal. 24 (2000) 33-41.

[19] K. Sreedhar, C.S.P. Sastry, M.N. Reddy, D.G. Sankar, Indian Drugs 32 (1995) 90-92.

[20] Y.K. Agrawal, K. Shivramachandra, B.E. Rao, Indian J. Pharm. Sci. 54 (1992) 218-221.

[21] B.V. Kamath, K. Shivram, East. Pharm. 35 (1992) 121-122.

[22] B.V. Kamath, K. Shivram, Indian Drugs 29 (1991) 50-52.

[23] J.M.M. Leitão and J.C.G. Esteves da Silva, unpublished results.

[24] H.A.L. Kiers, J.M.F. Ten Berge, R. Bro, J. Chemom. 13 (1999) 275-294.

[25] R. Tauler, Chemom. Intell. Lab. Syst. 30 (1995) 133-146.

[26] J.M.M. Leitão, J.C.G. Esteves da Silva, Anal. Chim. Acta 559 (2006) 271-280.

[27] J.M.D. Cueva, A.V. Rossi, R.J. Poppi, Chemom. Intell. Lab. Syst. 55 (2001) 125-132.

[28] A. Espinosa-Mansilla, A.M. de la Peña, H.C. Goicoechea, A.C. Olivieri, Appl. Spectrosc. 58 (2004) 83-90.

[29] J. Saurina, S. Hernández-Cassou, R. Tauler, A. Izquierdo-Ridorsa, J. Chemom. 12 (1998) 183-203.

[30] J. Saurina, S. Hernández-Cassou, R. Tauler, Anal. Chem. 69 (1997) 2329-2336.

[31] R. Tauler, A.K. Smilde, J.M. Hernshaw, L.W. Burguess, B.R. Kowalsky, Anal. Chem. 66 (1994) 3337-3344.

[32] A.K. Smilde, R. Tauler, J.M. Hernshaw, L.W. Burguess, B.R. Kowalsky, Anal. Chem. 66 (1994) 3345-3351.

[33] A. Niazi, J. Ghasemi, A. Yazdanipour, Anal. Lett. 38 (2005) 2377-2392.

[34] P.H. Março, M.A.B. Levi, I.S. Scarminio, R.J. Poppi, M.G. Trevisan, Anal. Sci. 21 (2005) 1523-1527.

[35] Y. Ni, C. Huang, S. Kokot, Chemom. Intell. Lab. Syst. 71 (2004) 177-193.

[36] M.V. Guterres, P.O.L. Volpe, M.M.C. Ferreira, Appl. Spectrosc. 58 (2004) 54-60.

[37] M.A.B. Levi, I.S. Scarminio, R.J. Poppi, M.G. Trevisan, Talanta 62 (2004) 299-305.

[38] S.R. Crouch, J. Coello, S. Maspoch, M. Porcel, Anal. Chim. Acta 424 (2000) 115-126.

[39] J.C.G. Esteves da Silva, C.J.S. Oliveira, Talanta 49 (1999) 889-897. 